\title{
In-Silico Screening Compounds of Brassica rapa ssp. chinensis as Potential Inhibitor of Neutral Amino Acid Transporter $\mathrm{B}^{\mathbf{0}} \mathrm{AT} 1$ as an Alternative Phenylketonuria Treatment
}

\author{
Nina Regina Nathania ${ }^{1,2}$, Jellyta Pricilla Mantow ${ }^{1,2}$, Elsa Rahmania Criswahyudianti ${ }^{1,2}$, Fachrur Rozi \\ Atamimi ${ }^{1}$, Fatchiyah Fatchiyah ${ }^{1,2 *}$ \\ ${ }^{1}$ Department of Biology, Faculty of Mathematics and Natural Sciences, Brawijaya University, Jalan Veteran, Malang, East Java, \\ Indonesia, 65145 \\ ${ }^{1}$ Research center of SMONAGENES, Brawijaya University, Jalan Veteran, Malang, East Java, Indonesia, 65145
}

Submission: 26 September 2021; Revised: 01 November 2021; Accepted: 03 December 2021

*Corresponding author: Fatchiyah Fatchiyah; e-mail: fatchiya@ ub.ac.id ; tel.: +62-341-575841

\begin{abstract}
Phenylketonuria (PKU) is known as a severe autosomal recessive disease caused by mutations in the expression enzyme, namely the PAH (Phenylalanine Hydroxylase) enzyme that causes the build-up of phenylalanine in the body. Untreated PKU affected brain damage and developmental problems. One of the strategies to reduce phenylalanine in the body is inhibiting BOAT1 activity using carotenoid and terpenoids compounds from Bok choy (Brassica rapa ssp.chinensis). In this study, we evaluated the nine carotenoid and terpenoid compounds from Bok choy as B0AT1 inhibitors. Nine Bok choy compounds, including alpha-carotene, beta-carotene, dimethylallyl pyrophosphate, isopentenyl pyrophosphate, lutein, neoxanthin, violaxanthin, geranylgeranyl diphosphate, and zeaxanthin were downloaded from PubChem database, while the 3D structure of BOAT1 was retrieved from Protein Data Bank RCSB. The compounds and BOAT1 were prepared by PyRx 0.8 version and Discovery Studio ver 21.1.1, then docked with Hex 8.0.0 and analyzed using Discovery Studio ver 21.1.1. This screening implies that three terpenoid compounds dimethylallyl pyrophosphate, isopentenyl pyrophosphate, and geranylgeranyl diphosphate interacts in $C$ domain of BOAT1 while six carotenoid compounds, alpha carotene, beta-carotene, lutein, neoxanthin, violaxanthin, and zeaxanthin interacts in A domain and have possibility to inhibit BOAT1, because it interact with same A domain and have a stronger binding energy than phenylalanine. Alpha carotene has a same residue with phenylalanine, Phe144, making it potentially greater than other compound as inhibitors. Brassica rapa ssp. chinensis is indeed good for consumption by people with phenylketonuria, but it is also necessary to do a further compound screening in other lowphenylalanine diet foods to know which one is better as alternative phenylketonuria treatment.
\end{abstract}

Keywords: alpa carotene, B0AT1, Brassica rapa, phenylalanine, phenylketonuria

\section{INTRODUCTION}

Phenylketonuria (PKU) is an inherited autosomal recessive congenital disease caused by a genetic mutation. Genetic mutations occur in a pair of alleles on chromosome 12 that encode genes for the expression of the PAH enzyme (Phenylalanine Hydroxylase), resulting in inactivation of the PAH enzyme and reduced performance of the enzyme in phenylalanine catabolism [1]. Deficiency of the PAH enzyme causes Phe build-up in the blood and brain. PKU sufferers cannot break down the amino acid phenylalanine into tyrosine, hence, the substance will accumulate in the body [2]. If left untreated, PKU sufferers will experience brain damage, intellectual disabilities, developmental problems, and seizures [3].

B0AT1, also known as SLC6A19, is a neutral amino acid transporter (AA0), which can be expressed in the intestine, especially in the jejunum [4]. Structurally SLC consists of 12 transmembrane helix, 10 helix formed a catalytic structure, the 11th and 12th helix emerge dimerization on the transporter. Then in its natural form in the intestine B0AT1 binds to the ACE2 receptor to form a heterodimer. Absorbed neutral amino acids consist of phenylalanine (Phe), leucin (Leu), methionine (Met), isoleucine (Ile), valine (Val), glycine (Gln), aspargine (Asn), cysteine (Cys), alanine (Ala), serin (Ser), threonine (Thr), glycine (Gly), tyrosine (Tyr), lysine (Lys), proline (Pro), tryptophan (Trp), and histidine (His). B0AT1 structurally similar to Leu due to the usage of active $\mathrm{Na}+$ transport as its mechanism $[5,6]$. Excessive absorption of AA0 on B0AT1 will cause malabsorption in the intestine. The presence of inhibition of B0AT1 shows a positive side for some cases of diseases such as restoring amino acid imbalances in phenylketonuria disease disorders [7].

Bok choy (Brassica rapa ssp chinensis) is one of the most consumed vegetables in Asia, including Indonesia [8]. The cultivation and consumption of Bok choy increases worldwide [9]. In implementing the Phe diet in PKU 
treatment, Bok choy is one of the foods that can be consumed without measuring its phenylalanine content in daily consumption due to the low content of phenylalanine $(<75 \mathrm{mg} / 100 \mathrm{~g})$. This does not affect the control of phenylalanine in the blood [10].

Bok choy contains beneficial compounds for health, such as carotenoids, which are useful as an antioxidants. Carotenoid is seen in vitamin $\mathrm{A}$ and helps to improve the function of the immune system in the body. These carotenoids include alpha- carotene, beta-carotene, lutein, neoxanthin, violaxanthin, and zeaxanthin [10]. Other ingredients are terpenoids which are isopentenyl diphosphate (IPP), dimethylallyl diphosphate (DMAPP), and geranylgeranyl diphosphate (GGPP) [11].

The purpose of this study was to screen Brassica rapa ssp chinensis compounds that have the activity of $\mathrm{B}^{0} \mathrm{AT} 1$ inhibitors. In finding alternative treatment solutions for PKU patients, an in-silico screening of Brassica rapa ssp chinensis compounds was carried out, which has potential as a phenylalanine transporter $\mathrm{B}^{0} \mathrm{AT} 1$ inhibitor in the intestinal epithelium.

\section{RESEARCH METHODS}

Data Mining and Preparation of Protein and Ligand

The $\mathrm{B}^{0} \mathrm{AT} 1$ (PDB ID 6M18) structure was downloaded from RCSB PDB website (www.rcsb.org) with PDB format. The ligand structure of phenylalanine (CID 6140) was downloaded from the PubChem website (www.pubchem.ncbi.nlm.nih.gov) with SDF format, the same is done with other ligands such as alpha carotene (CID 4369188), beta-carotene (CID 46783370), lutein (CID 5281243), neoxanthin (CID 5281247), violaxanthin (CID 448438), zeaxanthin (CID 5280899), dimethylallyl pyrophosphate (CID 647), geranylgeranyl diphosphate (CID 447277), and isopentenyl pyrophosphate (CID 1195). These nine active compounds of Bok choy had chosen by KNApSAcK database(http://www.knapsackfamily.com/KNAp $\mathrm{SAcK} /$ ). B0AT1 as protein was prepared by utilizing Biovia Discovery Studio Visualizer ver 21.1.1 software to remove native ligand and water molecules. Meanwhile, ligands were prepared using PyRx 0.8 software. The protein and ligand preparation results then stored in PDB (.pdb) format.

\section{Protein-Ligand Docking and Visualization}

Molecular docking of protein and ligand was done using HEX 8.0.0 software [4, 12]. The docking results were stored in PDB (.pdb) format and the binding energy was saved in TXT (.txt) format. Biovia Discovery Studio Visualizer ver 21.1.1 software was used to visualize the results of interactions between proteins and ligands (https://www.3ds.com/products-services/). The parameters that analyzed including the domain and bond energy, type of bond, and amino acid residues.

\section{RESULTS AND DISCUSSIONS}

\section{Interaction between Compounds and $\mathrm{B}^{\mathbf{0}} \mathrm{AT} 1$}

The interaction visualized in Figure 1 shows that three terpenoid group compounds bind to $\mathrm{C}$ domain of $\mathrm{B}^{0} \mathrm{AT} 1$, namely dimethylallyl pyrophosphate, isopentenyl pyrophosphate, and geranylgeranyl diphosphate, while compounds that bind to $\mathrm{A}$ domain of $\mathrm{B}^{0} \mathrm{AT} 1$ which is a transmembrane region are alpha carotene, betacarotene, lutein, neoxanthin, violaxanthin, and zeaxanthin, which are belong to the carotenoid group. The 3D interactions are shown in Figure 2. The interaction of phenylalanine with its transporter, $\mathrm{B}^{0} \mathrm{AT} 1$ shows Glu146 residue involved in hydrogen and electrostatic chemical bonds. The other residue Phe144 formed in the hydrogen bond. Hydrophobic bonds were formed at the between phenylalanine and $\mathrm{B}^{0} \mathrm{AT} 1$ has a binding energy of $-158.5 \mathrm{~kJ} / \mathrm{mol}$. Phenylalanine and $\mathrm{B}^{0} \mathrm{AT} 1$ bonds occur in the helix structure and domain $\mathrm{A}$ in $\mathrm{B}^{0} \mathrm{AT} 1$ (Figure 2 and Table 1).

Alpha-carotene binds to $\mathrm{B}^{0} \mathrm{AT} 1$ in $\mathrm{A}$ domain and part of the helix structure of $\mathrm{B}^{0} \mathrm{AT} 1$. This interaction results in a binding energy of -316.1 $\mathrm{kJ} / \mathrm{mol}$, lower than the $\mathrm{B}^{0} \mathrm{AT} 1$ interaction with phenylalanine. Low energy bonds tend to bind stronger. Based on the amino acid residue, alpha carotene has the same amino acid residue with phenylalanine, namely Phe144. Other amino acid residues are Phe141, Phe467, Ala202 and Cys203. All residues formed in hydrophobic bonds.

The interactions between beta-carotene and $\mathrm{B}^{0} \mathrm{AT} 1$ produce residues of Leu43, Leu46, Ile239, Ile309, Tyr231, and Phe312 involved in hydrophobic bonds with binding energy -354.5 $\mathrm{kJ} / \mathrm{mol}$ and the interaction happens on the A domain and the helix structure in $\mathrm{B}^{0} \mathrm{AT} 1$. Alpha carotene and beta-carotene are natural carotenoid compounds that act as precursors for vitamin A. Beta-carotene has more possibilities in the conversion process to cortisol (vitamin A) [13]. Another function of alpha-carotene and betacarotene is similar as other carotenoid compounds, it can act as an antioxidant, anticarcinogenic and can boost the immune system. Carotenoid compounds are able to bind to membrane lipids and proteins [14].

In contrast to other compounds that bind to the A domain such as phenylalanine, dimethylallyl pyrophosphate interacts to $\mathrm{B}^{0} \mathrm{AT} 1$ on the $\mathrm{C}$ 
domain. This bond occurs in the $\mathrm{B}^{0} \mathrm{AT} 1$ helix structure and produces a binding energy of -176 $\mathrm{kJ} / \mathrm{mol}$. The other amino acid residues are Ala222, Met210, Cys211 involved with dimethylallyl pyrophosphate in hydrophobic interactions and they bind into helix structure of B0AT1.

The other bond, hydrogen bond involved the Arg214 and Glu217 residues. Another compound that is bound to the $\mathrm{C}$ domain and the helix structure of $\mathrm{B}^{0} \mathrm{AT} 1$ is isopentenyl pyrophosphate. Results of the amino acid residues namely Met210, Thr218 and Lys221 interact through hydrogen bonds and produce binding energy of $165.3 \mathrm{~kJ} / \mathrm{mol}$.

All of the resulting amino acid residues bound to the helix structure of $\mathrm{B}^{0} \mathrm{AT} 1$ protein except for Met210. Isopentenyl diphosphate is one of the main constituents of a compound that functions as an isoprenoid precursor, condensing it into its isomeric compound, dimethylallyl pyrophosphate (DMAPP) with the help of the IPP isomerase enzyme [15].

Geranylgeranyl diphosphate interacts with B0AT1 and produces amino acid residues namely Met42, Leu46, Ile309, Val232 and Tyr231 which are formed by hydrophobic bonds. Like dimethylallyl pyrophosphate, this compound binds on the $\mathrm{C}$ domain and helix structure of $\mathrm{B}^{0} \mathrm{AT} 1$. This interaction creates a binding energy of $-219 \mathrm{~kJ} / \mathrm{mol}$. Geranylgeranyl diphospate is an isoprenoid compound that acts as a precursor to various compounds essential for vital metabolism (carotenoids, chlorophyll, gibberellins, etc.). This compound is formed from the plastic pathway GGPPP synthase (GGPPS). It is composed of five carbon chains (C5), IPP (Isopentenyl diphosphate) and the allylil isomer DMAPP (Dimetylallyl Pyrophosphate) [16].

Lutein is a compound that interacts with $\mathrm{B}^{0} \mathrm{AT} 1$ in the $\mathrm{A}$ domain of $\mathrm{B}^{0} \mathrm{AT} 1$. This bond produces amino acid residues, namely Cys200, Ala202, Cys203, Leu464, Leu199, Phe141, Trp195 and Try209 through hydrophobic bonds. All amino acid residues lie in the helix structure, except for Tyr209. The binding energy is -318.1 $\mathrm{kJ} / \mathrm{mol}$ emerged. Lutein has a structure consisting of a single carbon chain accompanied by carboncarbon double bonds, there is also a methyl side group. A cyclic hexenyl structure with hydroxyl groups can be seen at both ends of the carbon backbone. Lutein and zeaxanthin differ in this area due to the location of the methyl group on the long carbon chain and the double bond in the hexenyl ring [17].

Neoxanthin $\mathrm{B}^{0} \mathrm{AT} 1$ complex produced two amino acid residues, Cys 200 and Phe141. The two residues have hydrophobic interactions and produce $315.2 \mathrm{~kJ} / \mathrm{mol}$ binding energy. Neoxanthin interacts to the A domain and helix structure of $\mathrm{B}^{0} \mathrm{AT} 1$. Neoxanthin carotenoids derivates (other than lutein and violaxanthin) in the leaves of plants and its absorption capacity is close to violaxanthin [18].

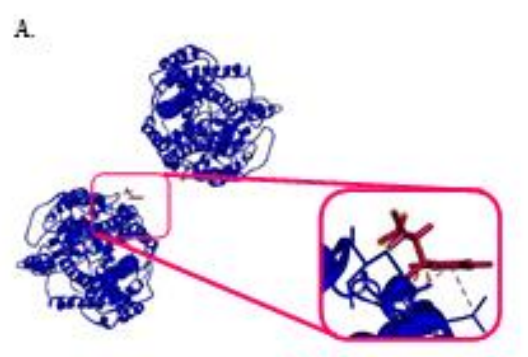

D.

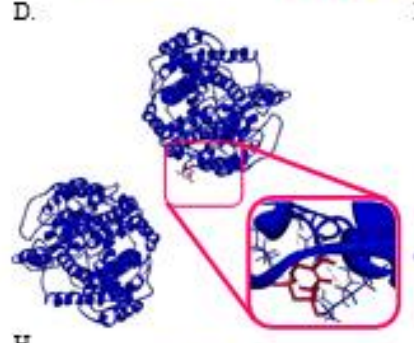

H.

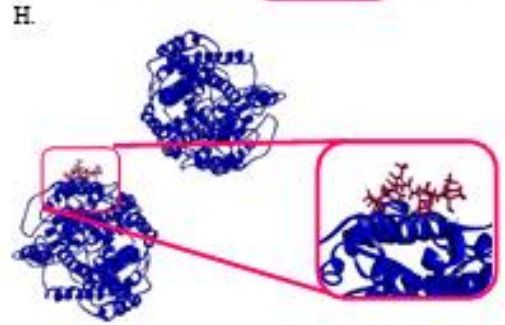

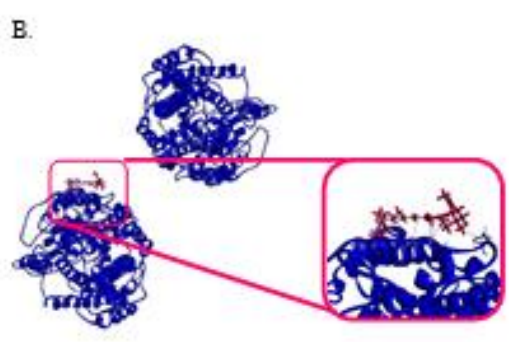

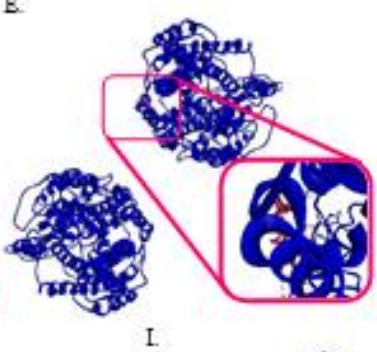

F.

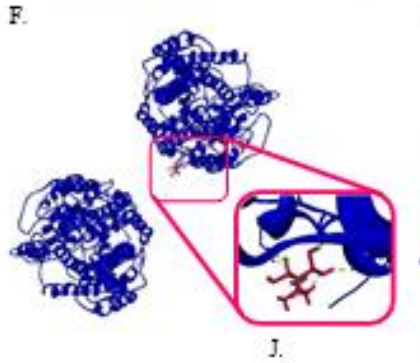

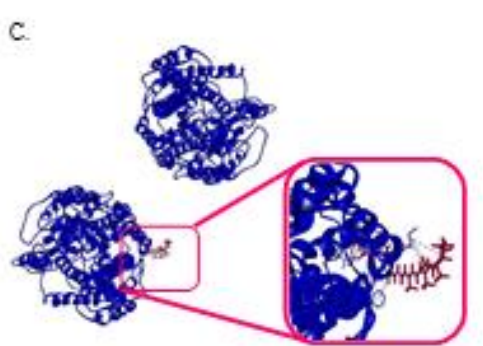

G.
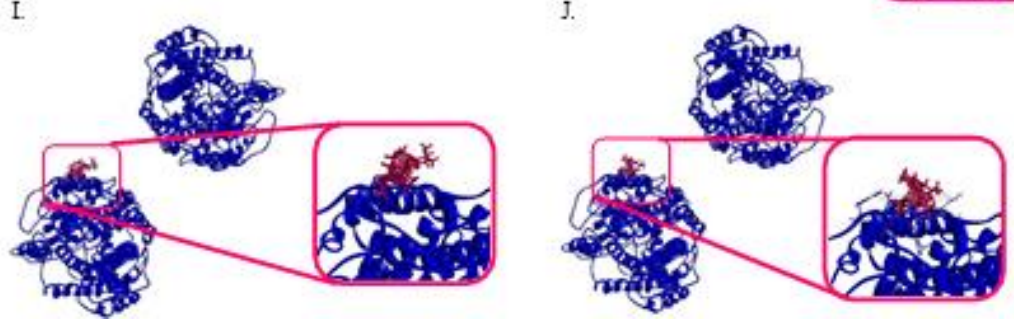

Figure 1. Three dimensional virtual molecular docking between $\mathrm{B}^{0} \mathrm{AT} 1$ with nine Brassica rapa compounds, A) phenylalanine; B) alpha-carotene; C) beta-carotene; D) dimethylallyl pyrophosphate; E) geranylgeranyl diphosphate; F) isopentenyl pyrophosphate; G) lutein; H) neoxanthin; I) violaxanthin; and J) zeaxanthin. Picture in the red box shows an enlarged image of the compound that is bound to the B0AT1 structure. 
A.



B.

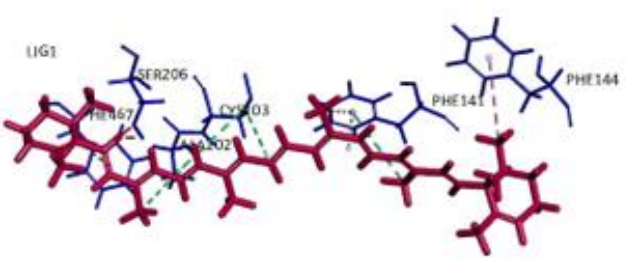

E.



H.





I.

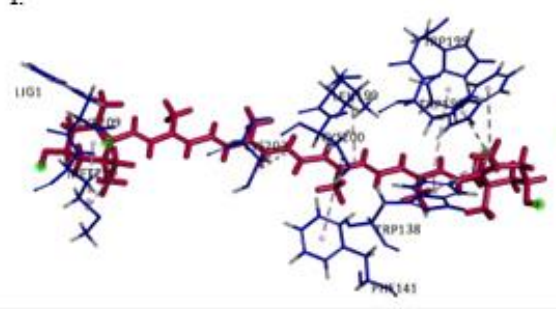

C.

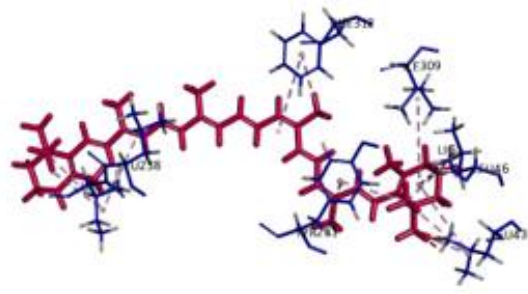

G.
F.

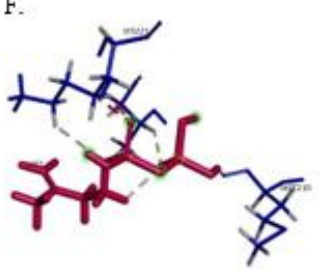

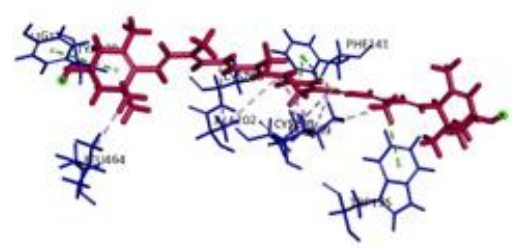

J.



Figure 2. The 3D interaction between $\mathrm{B}^{0} \mathrm{AT} 1$ and compounds: A) phenylalanine; $\mathrm{B}$ ) alpha-carotene; C) betacarotene; D) dimethylallyl pyrophosphate; E) geranylgeranyl diphosphate; F) isopentenyl pyrophosphate; G) lutein; H) neoxanthin; I) violaxanthin; and J) zeaxanthin.

Tabel 1. The interaction result of neutral amino acid transporter $\mathrm{B}^{0} \mathrm{AT} 1$ with phenylalanine and nine compounds of Brassica rapa ssp. chinensis.

\begin{tabular}{|c|c|c|c|c|}
\hline $\begin{array}{l}\text { Complexes (Binding } \\
\text { energy }(\mathbf{k J} / \mathbf{m o l}))\end{array}$ & Interactions & $\begin{array}{l}\text { Binding } \\
\text { Region/Domain }\end{array}$ & Category & Type \\
\hline \multirow{5}{*}{ Phenylalanine $(-158,5)$} & \multirow{2}{*}{$\begin{array}{l}\text { A:PHE1:HT2 - } \\
\text { A:GLU146:OE1 }\end{array}$} & \multirow[b]{2}{*}{ Topological } & Hydrogen & Salt \\
\hline & & & $\begin{array}{l}\text { Bond; } \\
\text { Electrostatic }\end{array}$ & $\begin{array}{l}\text { Bridge;Attractive } \\
\text { Charge }\end{array}$ \\
\hline & $\begin{array}{l}\text { A:PHE144:HA - } \\
\text { A:PHE1:OXT }\end{array}$ & Topological & $\begin{array}{l}\text { Hydrogen } \\
\text { Bond }\end{array}$ & $\begin{array}{l}\text { Carbon Hydrogen } \\
\text { Bond }\end{array}$ \\
\hline & A:PHE1 - A:PRO414 & Transmembrane & Hydrophobic & Pi-Alkyl \\
\hline & A:PHE1 - A:LEU415 & Transmembrane & Hydrophobic & Pi-Alkyl \\
\hline \multirow{6}{*}{ Alpha Carotene $(-316,1)$} & A:ALA202 - :LIG1:C26 & Transmembrane & Hydrophobic & Alkyl \\
\hline & A:CYS203 - :LIG1 & Transmembrane & Hydrophobic & Alkyl \\
\hline & A:PHE141 - :LIG1:C34 & Transmembrane & Hydrophobic & Pi-Alkyl \\
\hline & A:PHE144 - :LIG1:C6 & Topological & Hydrophobic & Pi-Alkyl \\
\hline & A:PHE467 - :LIG1:C17 & Transmembrane & Hydrophobic & Pi-Alkyl \\
\hline & A:LEU43 - :LIG1 & Transmembrane & Hydrophobic & Alkyl \\
\hline \multirow{7}{*}{ Beta-carotene $(-354,5)$} & A:LEU46 - :LIG1 & Transmembrane & Hydrophobic & Alkyl \\
\hline & A:ILE239 - :LIG1 & Transmembrane & Hydrophobic & Alkyl \\
\hline & A:ILE309 - :LIG1 & Transmembrane & Hydrophobic & Alkyl \\
\hline & :LIG1:C12 - A:LEU43 & Transmembrane & Hydrophobic & Alkyl \\
\hline & A:TYR231 - :LIG1:C24 & Transmembrane & Hydrophobic & Pi-Orbitals \\
\hline & A:PHE312 - :LIG1:C34 & Transmembrane & Hydrophobic & Pi-Orbitals \\
\hline & $\begin{array}{l}\text { C:ARG214:HH11 - } \\
\text { :LIG1:O3 }\end{array}$ & Topological & $\begin{array}{l}\text { Hydrogen } \\
\text { Bond }\end{array}$ & $\begin{array}{l}\text { Conventional } \\
\text { Hydrogen Bond }\end{array}$ \\
\hline \multirow{2}{*}{$\begin{array}{l}\text { Dimethylallyl } \\
\text { Pyrophosphate (-176) }\end{array}$} & $\begin{array}{l}\text { :LIG1:H11 - } \\
\text { C:GLU217:O }\end{array}$ & Topological & $\begin{array}{l}\text { Hydrogen } \\
\text { Bond }\end{array}$ & $\begin{array}{l}\text { Conventional } \\
\text { Hydrogen Bond }\end{array}$ \\
\hline & C:ALA222 - :LIG1:C4 & Transmembrane & Hydrophobic & Alkyl \\
\hline
\end{tabular}


Nina RN, Jellyta PM, Elsa RC, Fachrur RA, Fatchiyah F - In-Silico Screening Compounds of Brassica rapa ssp.

\begin{tabular}{|c|c|c|c|c|}
\hline $\begin{array}{l}\text { Complexes (Binding } \\
\text { energy }(\mathbf{k J} / \mathbf{m o l}))\end{array}$ & Interactions & $\begin{array}{l}\text { Binding } \\
\text { Region/Domain }\end{array}$ & Category & Type \\
\hline & :LIG1:C3 - C:MET210 & Transmembrane & Hydrophobic & Alkyl \\
\hline & :LIG1:C3 - C:CYS211 & Transmembrane & Hydrophobic & Alkyl \\
\hline & :LIG1:C - C:MET42 & Transmembrane & Hydrophobic & Alkyl \\
\hline & :LIG1:C - C:LEU46 & Transmembrane & Hydrophobic & Alkyl \\
\hline & :LIG1:C - C:LEU43 & Transmembrane & Hydrophobic & Alkyl \\
\hline & :LIG1:C - C:ILE309 & Transmembrane & Hydrophobic & Alkyl \\
\hline & :LIG1:C - C:VAL232 & Transmembrane & Hydrophobic & Alkyl \\
\hline & C:TYR231 - :LIG1:C & Transmembrane & Hydrophobic & Pi-Alkyl \\
\hline & $\begin{array}{l}\text { :LIG1:H10 - } \\
\text { C:MET210:O }\end{array}$ & Transmembrane & $\begin{array}{l}\text { Hydrogen } \\
\text { Bond }\end{array}$ & $\begin{array}{l}\text { Conventional } \\
\text { Hydrogen Bond }\end{array}$ \\
\hline \multirow{4}{*}{$\begin{array}{l}\text { Isopentenyl Pyrophosphate } \\
(-165,3)\end{array}$} & \multirow{2}{*}{$\begin{array}{l}\text { C:THR218:HB - } \\
\text { :LIG1:O6 }\end{array}$} & \multirow{2}{*}{ Topological } & \multirow{2}{*}{$\begin{array}{l}\text { Hydrogen } \\
\text { Bond }\end{array}$} & Carbon Hydrogen \\
\hline & & & & Bond \\
\hline & $\begin{array}{l}\text { C:LYS221:HE2 - } \\
\text { :LIG1:O }\end{array}$ & Topological & $\begin{array}{l}\text { Hydrogen } \\
\text { Bond }\end{array}$ & $\begin{array}{l}\text { Carbon Hydrogen } \\
\text { Bond }\end{array}$ \\
\hline & A:CYS200 - :LIG1 & Transmembrane & Hydrophobic & Alkyl \\
\hline \multirow{8}{*}{ Lutein $(-318,1)$} & A:ALA202 - :LIG1 & Transmembrane & Hydrophobic & Alkyl \\
\hline & A:CYS203 - :LIG1 & Transmembrane & Hydrophobic & Alkyl \\
\hline & :LIG1:C16 - A:LEU464 & Transmembrane & Hydrophobic & Alkyl \\
\hline & :LIG1:C23 - A:LEU199 & Transmembrane & Hydrophobic & Alkyl \\
\hline & :LIG1:C34 - A:CYS200 & Transmembrane & Hydrophobic & Alkyl \\
\hline & A:PHE141 - :LIG1:C34 & Transmembrane & Hydrophobic & Pi-Alkyl \\
\hline & A:TRP195 - :LIG1:C23 & Transmembrane & Hydrophobic & Pi-Alkyl \\
\hline & A:TYR209 - :LIG1 & Transmembrane & Hydrophobic & Pi-Alkyl \\
\hline \multirow{2}{*}{ Neoxanthin $(-315,2)$} & A:PHE141 - :LIG1 & Transmembrane & Hydrophobic & Pi-Alkyl \\
\hline & A:CYS203 - :LIG1 & Transmembrane & Hydrophobic & Alkyl \\
\hline \multirow{8}{*}{ Violaxanthin $(-300,4)$} & A:MET210 - :LIG1 & Transmembrane & Hydrophobic & Alkyl \\
\hline & :LIG1 - A:LEU199 & Transmembrane & Hydrophobic & Alkyl \\
\hline & :LIG1:C34 - A:CYS200 & Transmembrane & Hydrophobic & Alkyl \\
\hline & A:TRP138 - :LIG1:C12 & Transmembrane & Hydrophobic & Pi-Alkyl \\
\hline & A:PHE141 - :LIG1:C34 & Transmembrane & Hydrophobic & Pi-Alkyl \\
\hline & A:TRP195 - :LIG1 & Transmembrane & Hydrophobic & Pi-Alkyl \\
\hline & A:TRP196 - :LIG1:C12 & Transmembrane & Hydrophobic & Pi-Alkyl \\
\hline & A:TYR209 - :LIG1:C13 & Transmembrane & Hydrophobic & Pi-Alkyl \\
\hline \multirow{6}{*}{ Zeaxanthin $(-337,7)$} & :LIG1:C12 - A:MET210 & Transmembrane & Hydrophobic & Alkyl \\
\hline & :LIG1 - A:LEU199 & Transmembrane & Hydrophobic & Alkyl \\
\hline & A:TRP138 - :LIG1:C25 & Transmembrane & Hydrophobic & Pi-Alkyl \\
\hline & A:PHE141 - :LIG1 & Transmembrane & Hydrophobic & Pi-Alkyl \\
\hline & A:TRP195 - :LIG1:C19 & Transmembrane & Hydrophobic & Pi-Alkyl \\
\hline & A:TRP196 - :LIG1:C19 & Transmembrane & Hydrophobic & Pi-Alkyl \\
\hline
\end{tabular}

Violaxanthin interacts with $\mathrm{B}^{0} \mathrm{AT} 1$ in the A domain and helix structure and produces binding energy $-300.4 \mathrm{~kJ} / \mathrm{mol}$. The active sites of Violaxanthin - B ${ }^{0} \mathrm{AT} 1$ were Cys203, Met210, Leu199, Cys200, Trp138, Phe141, Trp195, Trp196, and Tyr209 through hydrophobic interactions. Violaxanthin is a major type of epoxycarotenoid biosynthesis present in higher plants and is usually found in due to its important role in the xanthophyll cycle [8]. Violaxanthin has an antioxidant capacity that is stronger than $\beta$ carotene and lutein [19]. Zeaxanthin binds to B0AT1 and produces amino acid residues, namely Met210, Leu199, Trp138, Phe141, Trp195, and Trp196 involved in hydrophobic interactions. The resulting bond energy is $-337.7 \mathrm{~kJ} / \mathrm{mol}$. This 
interaction has binding on domain $\mathrm{A}$ and the helix structure of $\mathrm{B}^{0} \mathrm{AT} 1$.

Zeaxanthin is a type of non-provitamin A carotenoid that has an oxygen molecule. This compound consists of 40 hydroxylated carbons which are the same as lutein. Therefore, both of them are included in the xanthophyll group. These compounds are useful as a deterrent from oxidative damage to proteins, lipids, or DNA by using other antioxidant mechanisms [20].

\section{Screening the potential of nine compounds as an inhibitor of $\mathrm{B}^{\mathbf{0}} \mathrm{AT} 1$}

Based on the analysis of molecular docking results, it was shown that all the nine compounds screened had lower binding energy values compared to phenylalanine against B0AT1 with the majority forming hydrophobic bonds. There are no unfavorable bonds in all the bonds between the compounds and $\mathrm{B}^{0} \mathrm{AT} 1$. Six compounds, alpha-carotene, beta-carotene, lutein, neoxanthin, violaxanthin, and zeaxanthin bind B0AT1 in domain A the same as phenylalanine. Almost all of these six carotenoid compounds bind to amino acid residues on transmembrane region. The structure of $\mathrm{B}^{0} \mathrm{AT} 1$ has two main region, topological and transmembrane. Topological domain, is a domain where the regulation of gene expression occurs. This behavior arises to limit the interaction of cis sequence regulator and its targeted gene [21]. The study of Spitz exhibits that topological domain can be matched with the domain regulator [22]. The transmembrane region located in B0AT1 is where the bound protein and amino acid residual [21]. It means that interaction between compounds into transmembrane region can disturb the interaction of amino acid and the transporter, B0AT1. Meanwhile, three terpenoid compounds, namely dimethylallyl pyrophosphate, geranylgeranyl diphosphate, and isopentenyl pyrophosphate bind to the $\mathrm{C}$ domain of $\mathrm{B}^{0} \mathrm{AT} 1$.

These compounds also exhibit the top three high energy binding values. In addition, none of the residues were the same as the phenylalanine residue in $\mathrm{B}^{0} \mathrm{AT} 1$. This indicates that the three compounds have the lowest probability of being inhibitors of phenylalanine in binding to $\mathrm{B}^{0} \mathrm{AT} 1$.

\section{CONCLUSION}

This study indicated that six of nine Bok choy compounds, alpha-carotene, beta-carotene, lutein, neoxanthin, violaxanthin, and zeaxanthin bind $\mathrm{B}^{0} \mathrm{AT} 1$ in domain $\mathrm{A}$ the same as phenylalanine. Furthermore, alpha-carotene has same active sites with phenylalanine, which was Phe144, indicating alpha-carotene might has similar function with phenylalanine. Nevertheless, Bok choy is recommended to consume as a low phenylalanine diet food.

\section{ACKNOWLEDGEMENT}

We gratefully thank the member of the research center of SMONAGENES, all of our bioinformatics lecturers, laboratory assisstants, for helping us finish this research, and Nadya Tasya Mellivirrisya Putri for english corrections.

\section{REFERENCES}

[1] Harding, C. O. 2010. New era in treatment for phenylketonuria: pharmacologic therapy with sapropterin dihydrochloride. Biologics: Target \& Therapy. 4: 231-236.

[2] Hafid, N. A., \& J. Christodoulou. 2015. Phenylketonuria: a review of current and future treatments. Transl Pediatr. 4(4): 304317.

[3] Wegberg, A. M. J., A. MacDonald, K. Ahring, A. Bélanger-Quintana, N. Blau, A. M. Bosch, A. Burlina, J. Campistol, F. Feillet, M. Giżewska, S. C. Huijbregts, S. Kearney, V. Leuzzi, F. Maillot, A. C. Muntau, M. Rijn, F. Trefz, J. H. Walter, \& H. J. Spronsen. 2017. The complete european guidelines on phenylketonuria: diagnosis and treatment. Orphanet Journal of Rare Diseases. 12(1): 162.

[4] Jando, J., S. M. R. Camargo, B. Herzog, \& F. Verrey. 2017. Expression and regulation of the neutral amino acid transporter $\mathrm{B}^{0} \mathrm{AT} 1$ in rat small intestine. PLOS ONE, 12(9): $\mathrm{e} 0184845$.

[5] Javed, K., Q. Cheng., A. J. Carroll., T. T. Truong., \& S. Broer. 2018. Development of Biomarkers for Inhibition of SLC6A19 $\left(\mathrm{B}^{0} \mathrm{AT} 1\right)-\mathrm{A}$ Potential Target to Treat Metabolic Disorders. International Journal of Molecular Sciences. 19(11): 3597.

[6] Kreul, C. G., A. Pommereau., S. Ruf., J. L. Kane Jr., T. Kuntzweiler., G. Hessler., C. K. Engel., P. Shum., L. Wei., J. Czech., \& T. Licher. 2021. A Solid Supported MembraneBased Technology for Electrophysical Screening of $\quad \mathrm{B}^{0} \mathrm{AT} 1$-Modulating Compounds. SLAS Discov. 26(6): 783-797.

[7] Yadav, A., N. Shah, P. K. Tiwari, K. Javed, Q. Cheng, I. S. Aidhen, \& S. Bröer. 2020. Novel chemical scaffolds to inhibit the neutral amino acid transporter $\mathrm{B}^{0} \mathrm{AT} 1$ (SLC6A19), a potential target to treat metabolic diseases. Front. Pharmacol. 11(140).

[8] Priadi, D., \& F. Nuro. 2017. Seedling production of Pak Choy (Brassica rapa L.) using organic and inorganic nutrients. Biosaintifika: Journal of Biology and Biology Education. 9(2): 217-224.

[9] Jeon, J., C. J. Lim, J. K. Kim, \& S. U. Park. 2018. Comparative metabolic profiling of green and purple pakchoi (Brassica rapa 
subsp. chinensis). Molecules. 23(7): 1613.

[10] MacDonald, A., A. M. J. Wegberg, K. Ahring, S. Beblo, A. B. Quintana, A. Burlina, J. Campistol, T. Coskun, F. Feillet, M. Gizewska, S. C. Huijbregts, V. Leuzzi, F. Maillot, A. C. Muntau, J. C. Rocha, C. Romani, F. Trefz, \& F. J. Spronsen. 2020. PKU dietary handbook to accompany PKU guidelines. Orphanet Journal of Rare Diseases. 15(171).

[11] Block, A. K., M. M. Vaughan, E. A. Schmelz, \& S. Christensen. 2019. Biosynthesis and function of terpenoid defense compounds in maize (Zea mays). Planta: An International Journal of Plant Biology. 249(1): 21-30.

[12] Vishnuvarthan, V. J., K. S.Lakshmi., \& A. R. Srividya. 2017. In-Silico Screening of Flavonoids Targeted for Death Receptors in Cancer by Using Hex Molecular Docking. $J$ Young Pharm. 9(2): 168-171.

[13] Eldahshan, O. A., \& A. N. B. Singab. 2013. Carotenoids. Journal of Pharmacognosy and Phytochemistry. 2(1): 225-234.

[14] Reboul, Emmanuelle. 2019. Mechanisms of Carotenoid Intestinal Absorption: Where Do We Stand?. Nutrients. 11(4): 838

[15] Raja, Rathinam., S. Hemaiswarya., K. Arunkumar., I. S. Carvalho. 2021. Algae for Food: Cultivation, Processing and Nutritional Benefits. CRC Press. Boca Raton.

[16] Zhou, F., C. Y. Wang, M. Gutensohn, L. Jiang, P. Zhang, D. Zhang, N. Dudareva, \&
S. Lu. 2017. A recruiting protein of geranylgeranyl diphosphate synthase controls metabolic flux toward chlorophyll biosynthesis in rice. Proc Natl Acad Sci U S A. 114(26): 6866-6871.

[17] Mazumder, A., P. Prabuthas, A. Giri, \& H. N. Mishra. 2014. Major food grade pigments from microalgae and their health benefits. Indian Food Industry Mag. 33(4): 19-30.

[18] Giossi, C., P. Cartaxana, \& S. Cruz. 2020. Photoprotective role of neoxanthin in plants and algae. Molecules. 25(20): 4617.

[19] Cataldo, V. F., N. Arenas, V. Salgado, C. Camilo, F. Ibanez, \& E. Agosin. 2020. Heterologous production of epoxycarotenoid violaxanthin in Saccharomyces cerevisiae. Metabolic Engineering. 59: 53-63.

[20] Gammone, M. A., G. Riccioni, \& N. D'Orazio. 2015. Marine carotenoids against oxidative stress: effects on human health. Marine Drugs. 13(10): 6226-6246.

[21] Margheritis, E., F. G. Imperiali, R. Cinquetti, A. Vollero, G. Terova, S. Rimoldi, R. Girardello, \& E. Bossi. 2016. Amino acid transporter B ${ }^{0}$ AT1 (slc6a19) and ancillary protein: impact on function. Pflugers Archiv - European Journal of Physiology. 468(8): 1363-1374.

[22] Symmons, O., V. V. Uslu, T. Tsujimura, S. Ruf, S. Nassari, W. Schwarzer, L. Ettwiller, \& F. Spitz. 2014. Functionl and topological characteristic of mammalian regulatory domains. Genome Research. 24(3): 390-400. 